\title{
Parametric Designing of Structures with Arc Behavior for Multipurpose Exhibition in Tehran
}

\author{
Mohsen Afshari, \\ Department of Digital Architecture Technology, \\ Faculty of Architecture, Pars University, Tehran, Iran \\ Prof.Mahmood Golabchi, \\ Department of Architecture Technology, \\ Faculty of Architecture, Pars University, Tehran, Iran \\ Dr.Katayoun Taghizadehazari, \\ Department of Architecture Technology, \\ Faculty of Fine Arts, University of Tehran, Tehran, Iran
}

\begin{abstract}
Parametric design method is among the new design methods, especially in digital architecture technology. In this method, one can have access to all structural and architectural components of the design up to the last designing stage. The purpose of the study was parametric design of the structures with arc behavior for the multipurpose exhibition in Tehran. Structural design in this study was initially done by formulating the structure with Rhino Vault Plugin tailored to the rope behavior and after obtaining the desired form, analyzing the structural behaviors and defining the appropriate materials for the design, as well as the appropriate cross-sectional area by Karamba plugin were performed. Loadings and constraints in design and control of the structure are in accordance with the necessary standards, especially the sixth and ninth articles of the National Building Regulations. In the interior design, neighbors - a large park, the flower fair and the spacious space for various exhibitions - and booth designs are considered. Iranian-Islamic models inspire designing the patterns used in the ceiling and each pattern is designed for its particular location by parametric design. Additionally, using different software applications, the performance of the project against wind and earthquake and the lighting of the projects were examined as well.
\end{abstract}

Keywords: parametric design, structures with arc behavior, multipurpose exhibition

\section{Introduction}

With increase in Tehran population and scarcity of exhibition spaces in Tehran, the formation of multipurpose exhibitions to improve sociocultural and economic issues has turned into a need and the establishment of new exhibition spaces will help solve these issues. Designing exhibition spaces has various standards and methods that can vary according to the functions. Architecture and structure engineering in most projects and designs are examined completely separately, but in exhibition design these two are combined and the structure itself can have architectural function and given the sensitivity of the design according to standards; since the exhibitions are in the category of risk group 2, while architectural design of this project, the architectural design should be considered.

Recently, there have been several interdisciplinary trends in various sciences and disciplines that deal with the issues and gaps of the interrelated two disciplines. In this project, this problem tackled, and the aesthetic issues are considered by obtaining an optimal form and appropriate structural sections.

Parametric design method is a new design method especially in digital technology architecture. In parametric design, one can have access to all architectural and design components of the project until the last design stage. Moreover, if needed, its parameters are controlled or changed, which is one of the requirements and prerequisites to optimize a design, because in optimization operation we need to have several variables that change with a fixed number that is the base to reach the most ideal number that can be the location of the structure, or the diameter or thickness of the material, and so on.

Pure compression behavior forms have unique features like the ability to create large openings, eliminate columns and create a flexible architectural environment, as well as the use of the existing materials with compressive behavior. In designing exhibitions, one needs large openings and the removal of intruding pillars and the creation of proper commuting spaces and beautiful and modern design. Overall, the classification for compression structures is as follows: arches, vaults, and domes. According to previous studies, we have found that the arches are of the most used structural systems in history (Golabchi, M., Taghizadeh, K., Golabchi, M.R., 
2013; 175), and regarding the selection of the appropriate form, we know that a resistant structure gets its strength more from the form and the structure shape rather than the materials it is made of (Golabchi, M., Taghizadeh, K., Golabchi, M.R., 2013; 175). Nowadays, architects and engineers have felt the need for more interaction in their designs, and each one tries to acquire knowledge in this field. In the meantime, software is a great help to solve this problem. In this study, using various software and plugins of the software, the architectural and structural design of the exhibition is done trying. The effort is to optimize the structure for weight loss and being economical by selecting the appropriate section, and the structure analysis, to be fully functional, will be in accordance with existing standards in Iran, trying to meet all these needs and issues.

\section{Literature review}

\section{Exhibition space design}

Exhibitions are the key component of marketing mix and communication, as they bring together the buyers and sellers from around the world in an appropriate place to examine, compare, buy and upgrade goods (Association of Exhibitors, 2003, p. 1). No other intermediary provides the opportunity for the company to achieve many of its goals by one action. Thus, many major companies consider exhibition an important part of their marketing plans (Skape, 2003, p. 1). Moreover, studies show that the relationship between the exhibitor and the visitor can last and be effective two years after the air. Currently, the exhibition is so distant from its initial form, and its educational, promotional and informational functions have become so significant.

The studies show that at exhibitions, $76 \%$ of the visitors asks questions about the product, $24 \%$ sign the purchase order, and $64 \%$ of them talk about the exhibition with at least 6 other people (Goldberg \& Lorimer, 2001, p. 4).

In the modern marketing, the marketing mix is considered as a very important issue, meaning that a set of marketable control tools is used that combines them to respond to the target market. In other words, the marketing mix contains all the activities that the company does to affect the demand, which includes the four variables: product, price, distribution, and extension. These are among the important missions of the exhibition (Kuttler\& Armstrong, 1999, p. 80).

\section{Parametric design}

Algorithms have been widely used in architecture throughout the history. Even before the concept of algorithm was linked to computer, there were rules and guidelines in the architecture that were actually the very algorithms (Golabchi, 2011, 14). In algorithmic architecture, it is tried to influence the parameters affecting the physical behavior of the building (such as structures and materials) in the process of continuous analysis, affecting the architecture in time and correct the design in feedback cycles. A designer's insistence in advancing a form-spatial idea and then the engineering team's demand to build that project are not the good case of architecture anymore. Algorithmic cycles of analytical design have dealt with examination and production and after various analyses on the design, deficiencies, problems and mistakes are done away with (Khabazi, 2011; 90).

The base of parametric architecture in designing building structures is the plants and imitation of biological factors, where aesthetic and operational values are higher than normal samples. Parametric or component formulation means the process based on the proposed solutions to spatial (multidimensional) problems using changing variables by introducing a set of rules that describe defects and barriers form that leads to genuine and productive ideas about the process of architectural design. Today, the most commonly used method of computer use in architectural design is the combination of early design and early design decisions, mentally and manually, and then extending and expanding those ideas through computer software (Golabchi, 2011; 15).

Parametric design allows the architects to explore the complex geometric and spatial designs to develop complex geometric and spatial architectural solutions. A parametric design is composed of a set of variables and sets of relationships that define a form, which can be manipulated by changing specific parameters and adjusting the data (Golabchi, 201; 17). In fact, in these types of designs, all the different volumes are the members of one family, which, while having a uniform shape, are different in some parameters (Golabchi, 2011; 132). Among the different digital design approaches, parametric design has become a trend in contemporary architectural design (Nicknam and Eslamian, 2010).

One of the oldest examples of parametric design can be the upside-down model of churches by Antoni Gaudi. Another parametric design is the conceptual parameter where only design parameters are specified. Another example is the structural parametric design of environments that have pre-built 3D objects.

\section{Structures with arch behavior}

According to the conducted studies, various types of structures with compressive behavior have been created from the past, known as structures with arch behavior (compressive behavior). The behavior of all of them is generally based on rope behavior curve, where only tensile stress exists, and by inverting them, we obtain pure stress pressure. As the slope of the arch increases, the dead load increases and the live load, such as snow, slow 
down due to slipping. Radial arches in a circular plan are arranged under gravity loads. The uniform load curve distributed horizontally is a second-order curve whose tangent lines collide at an arc-height in the arc-foot. Under the triangular load of the power lines, a third degree curve forms, with the tangents of the starting point of the curve reaching three times the height (Wahl, 2007).

The more ideal the arch form is in terms of structure, the greater the possibility of unused space for the arches to function, and this space will require more heating, cooling and ventilation (Golabchi, M., Taghizadeh, Golabchi, M.R., 2013; 179).

The arches with a rope curve shape are very similar to the arches. The curvature of an arch is drawn along a horizon and a curved plate is formed. Like the arches, the form of the vault should follow the rope curve to prevent bending stresses (Golabchi, M., Taghizadeh, Golabchi, M.R., 2013; 194).

Domes, like arches, belong to the family of pressure systems. Obviously, the domes are synclastic shells; i.e. they are bent in two directions perpendicular to the bottom, the shape of the dome is drawn from the rotation of a vault. In terms of structural behavior of domes, one can state that they have very similar structures to that of arches, but with the advantage that the stability of domes in space is greater than the arches. A resistant structure gets its strength more from the form and the structure shape rather than the materials it is made of (Golabchi, M., Taghizadeh, K., Golabchi, M.R., 2013; 209).

\section{Site profile}

The site is located in Tehran, at Keshavarz Boulevard and Hijab Street intersection, next to LalehBoostan. Its area is 9,200 square meters, the length and width of the land is $80^{*} 115$, the land gradient is very negligible, and the site spreads, northwest southeast.

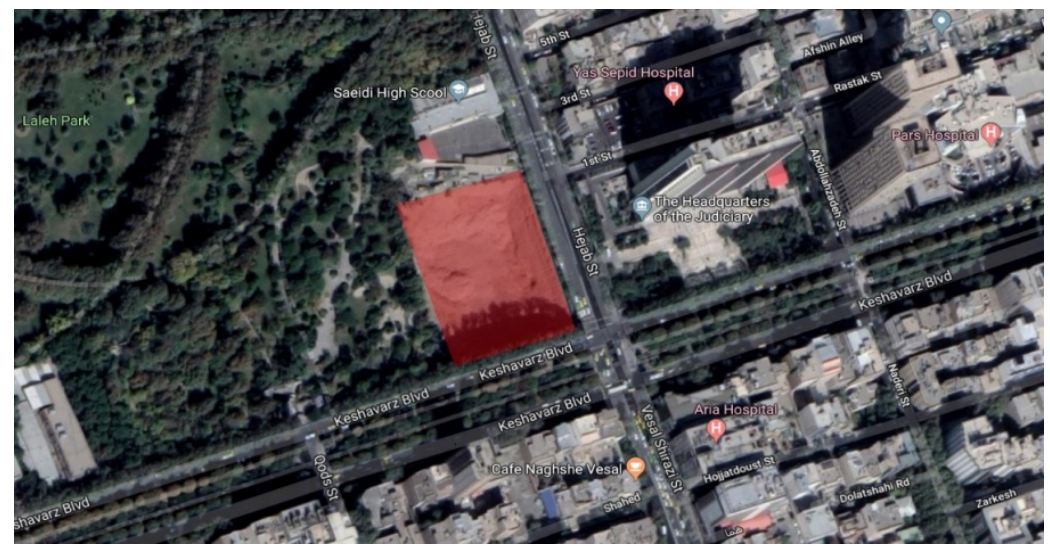

Figure 1: Geographic specifications of the site

The site condition is such that it does not have good conditions regarding the sunlight and its lightening side is shorter. Given its 17-degree rotation, it affects designing. Now, the site is analyzed.
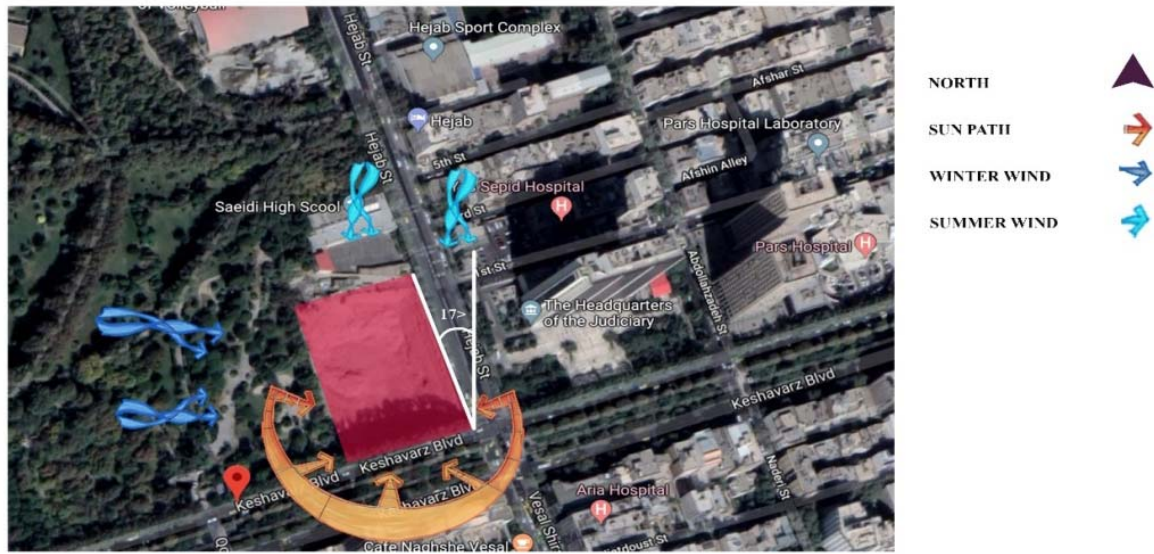

Figure 2: Climate analysis of the project 

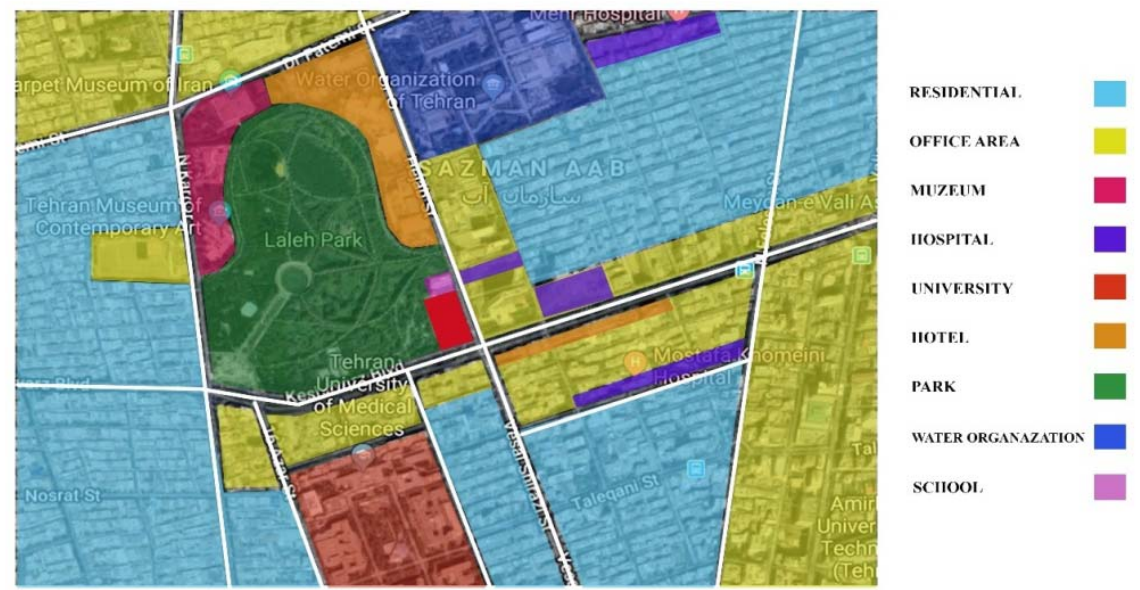

Figure 3: Analysis the site neighboring

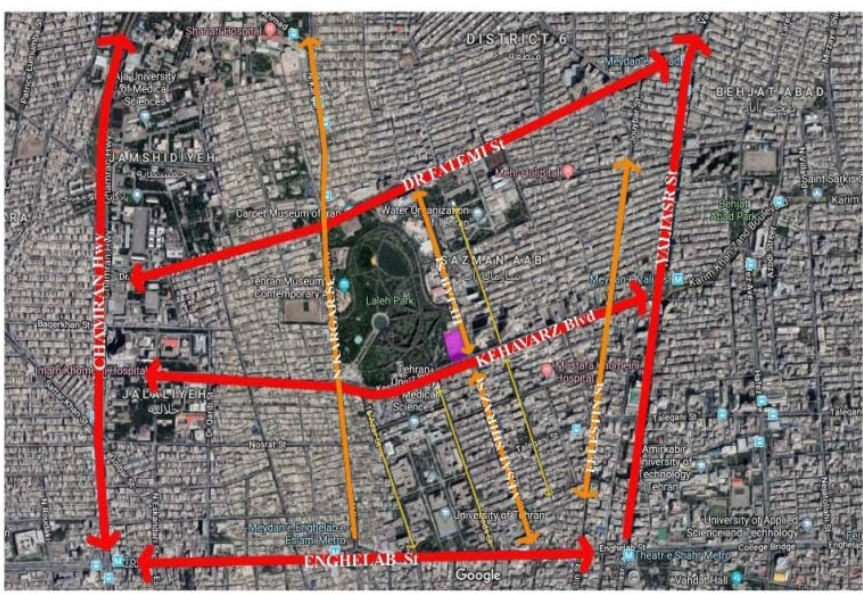

FIRST ACCESS

SECOND ACCESS

TIIIRD ACCESS

Figure 4: Analysis of the access to the site

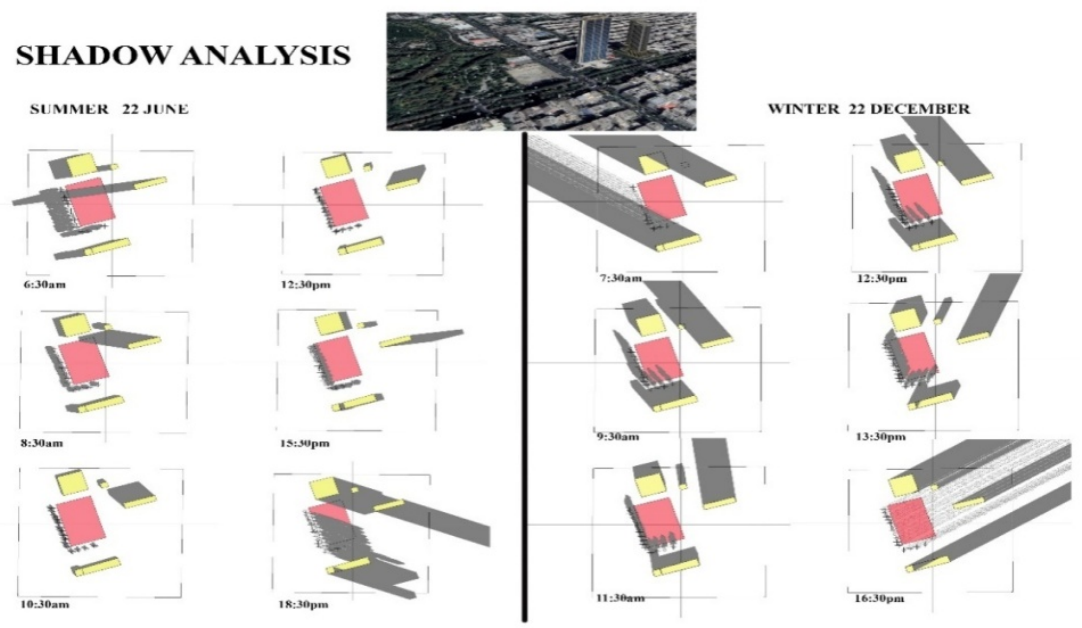

Figure 5: Analysis of the site shading

Structural design in this study was initially done by formulating the structure with Rhino Vault Plugin tailored to the rope behavior and after obtaining the desired form, analyzing the structural behaviors and defining the appropriate materials for the design, as well as the appropriate cross-sectional area by Karamba plugin were performed. In the next step, optimization of the structure for the diameter and thickness of the materials walls used in the design is proportional to the weight and deflection of the structure and the final structure is obtained. Loadings and constraints in design and control of the structure are in accordance with the necessary standards, especially the sixth and ninth articles of the National Building Regulations. 


\section{Structural parameters}

\section{Results}

\section{Wind analysis}

According to the site analysis and surveys, the maximum amount of winter disturbing wind is from the west and at a speed of $16 \mathrm{~m} / \mathrm{s}$. By examining the wind and wind speed using climate consultant software and obtaining the necessary information, we designed the model of wind impact on the structure and the form obtained with the Autodesk Flow Design software, in terms of structural form and the effect of wind force on the structure the final results were attained. Firstly, the wind impact is generally examined (Fig. 6) and (Fig. 7) and (Fig. 8). According to the general survey, the shape of the design passes wind well, and does not impose significant pressure on the structure. Thus, in the loading section, we ignore the wind power calculations.

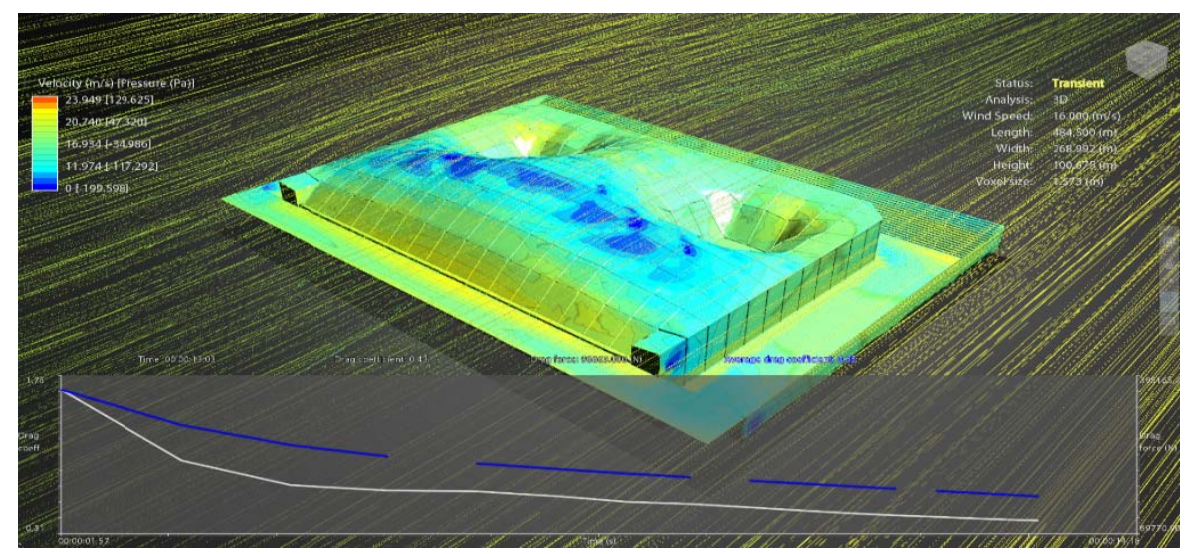

Figure 6: Modeling the effect of wind on the structure

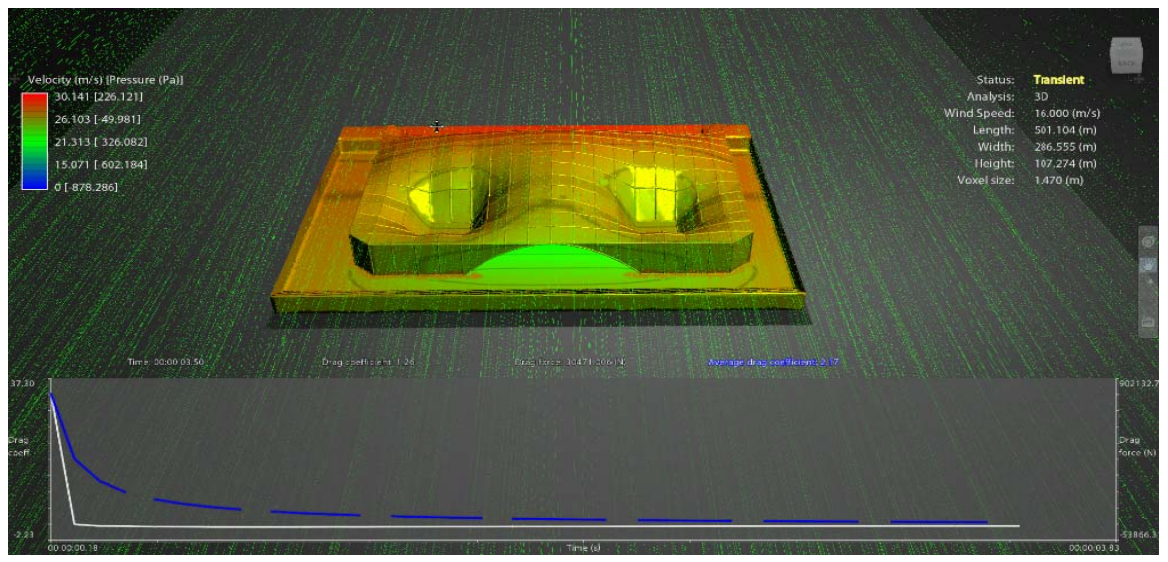

Figure 7: Modeling the effect of wind on the structure

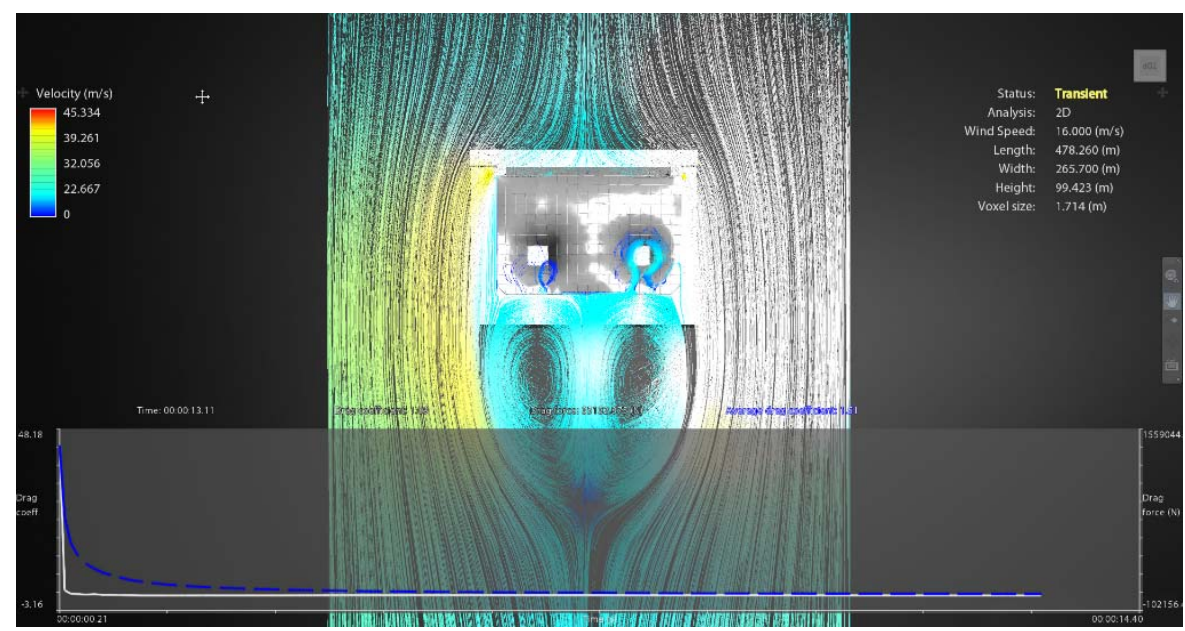

Figure 8: Modeling the effect of wind on the structure 


\section{Loading}

\section{Structural modeling with Karamba}

To use this plugin, one must first transfer the output from Rhino Vault Plugin exactly with the same form and without changing to Grass Hopper and then to Karamba. One can get three types of outputs fromRhino Vault, one of which is a network composed of curves and points. Here, by getting this mesh network and turning it into the structure, the work process starts (Figure 9)

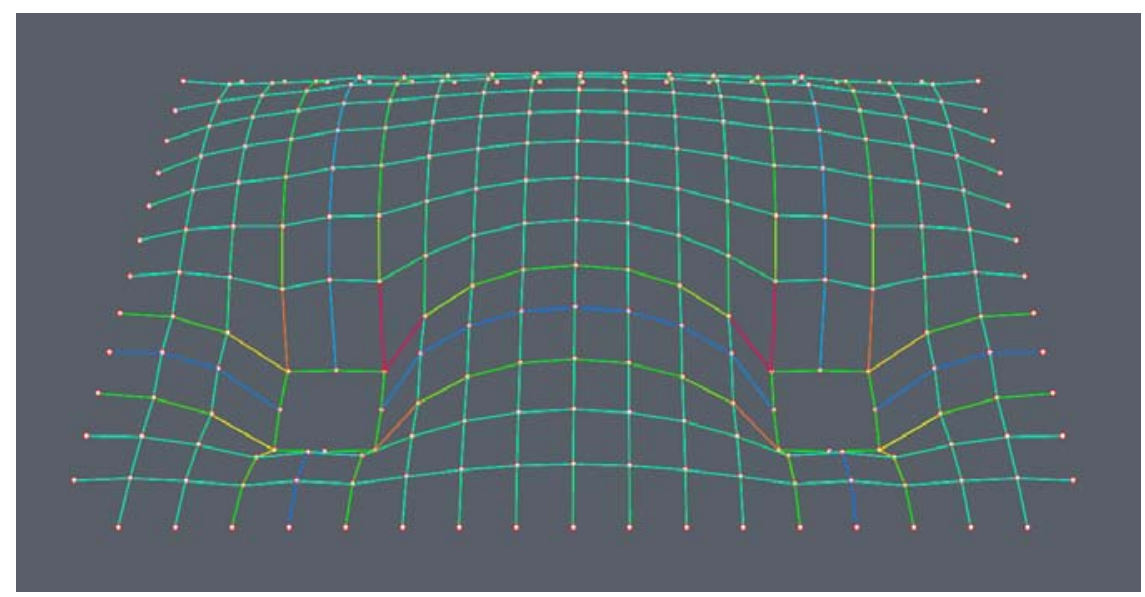

Figure 9: Rhino Vault output mesh network

To convert a volume or geometric form and load it in Karamba, one must define the beams and elements, as well as the sections and materials, and then define the type of materials and sections for the beams and bearing elements. Then, we calculate the live load (Table 1).

Table 1: Live load on the project

\begin{tabular}{|c|c|c|c|}
\hline Row & Live load $\left(\mathrm{Kn} / \mathrm{m}_{2}\right)$ & Overall load surface $\left(\mathrm{m}_{2}\right)$ & Extended live load $\left(\mathrm{Kn} / \mathrm{m}_{2}\right)$ \\
\hline 1 & 2844 & 5688 & 0.5 \\
\hline
\end{tabular}

This extended load is as 74 point load and uniformly on the roof and at the intersection of beams on the structure.

\section{Selection of materials and their dimensions}

Materials of this project are ST-37 steel of S235 type. Moreover, the selected section is of pipe type. Here, it is necessary to obtain the most section suitable in proportion to the loads loaded and to create the least weight for the structure, which is the dead load of the building. In doing so, firstly the permitted deflection must be determined (Table 2).

Table 2: Permitted deflection of the project

\begin{tabular}{|c|c|c|}
\hline Row & Maximum permitted deflection (m) & Length of the largest opening (m) \\
\hline 1 & 0.383 & 92 \\
\hline
\end{tabular}

After obtaining the permitted deflection, it is necessary to select the most suitable section, where optimization with Galapagos Plugin is used. By obtaining the numbers related to the dead load sections of the project, the stability of the project is reexamined by combining loads and by examining the graphical graphs of the project output (Fig. 10) and (Fig. 11) and the resulting numbers, the project stability is examined (Table 2).

Table 2: Project stability

\begin{tabular}{|c|c|c|c|c|}
\hline Row & $\begin{array}{c}\text { deflection after } \\
\text { loading }(\mathrm{m})\end{array}$ & $\begin{array}{c}\text { Structure final } \\
\text { weight }(\mathrm{kg})\end{array}$ & $\begin{array}{c}\text { Section } \\
\text { diameter }(\mathrm{Cm})\end{array}$ & $\begin{array}{c}\text { Section } \\
\text { thickness }(\mathrm{mm})\end{array}$ \\
\hline 1 & 0.350 & 556239 & 48 & 21 \\
\hline
\end{tabular}




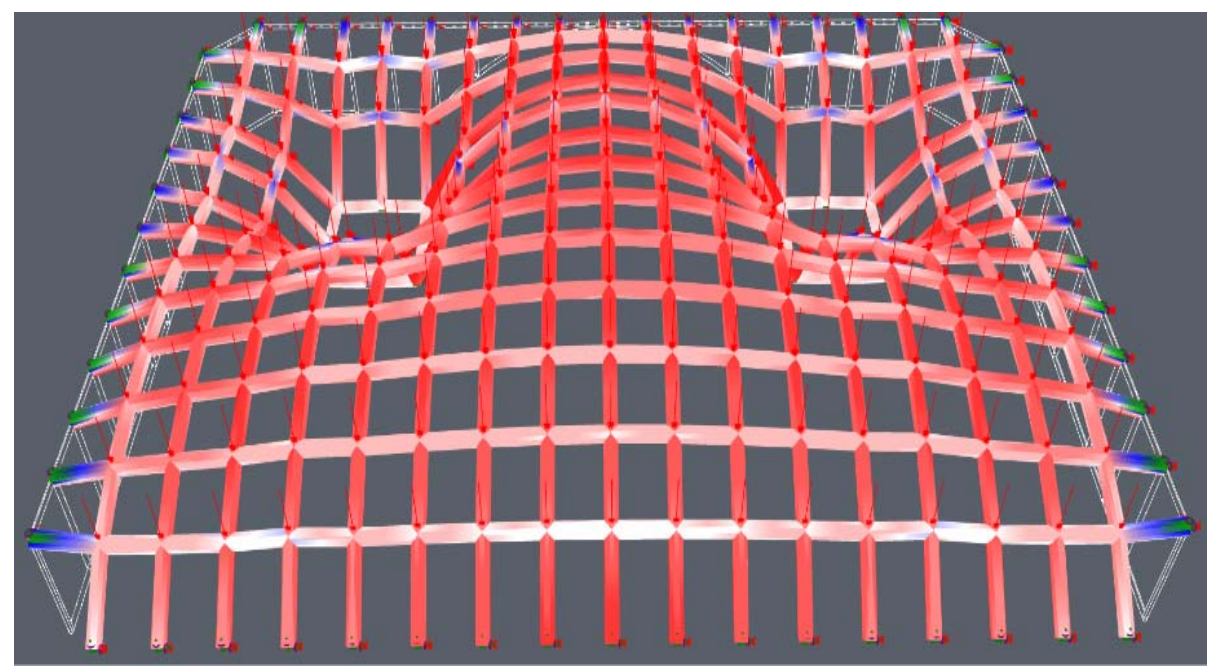

\begin{tabular}{|l}
\hline stress[kN/cm2] \\
\hline$-1.62 \mathrm{e}+02$ \\
\hline$-1.42 \mathrm{e}+02$ \\
\hline$-1.22 \mathrm{e}+02$ \\
\hline$-1.01 \mathrm{e}+02$ \\
\hline$-8.10 \mathrm{e}+01$ \\
\hline$-6.08 \mathrm{e}+01$ \\
\hline$-4.05 \mathrm{e}+01$ \\
\hline$-2.03 \mathrm{e}+01$ \\
\hline $5.82 \mathrm{e}-15$ \\
\hline $5.01 \mathrm{e}+00$ \\
\hline $1.00 \mathrm{e}+01$ \\
\hline $1.50 \mathrm{e}+01$ \\
\hline $2.00 \mathrm{e}+01$ \\
\hline $2.51 \mathrm{e}+01$ \\
\hline $3.01 \mathrm{e}+01$ \\
\hline $3.51 \mathrm{e}+01$ \\
\hline$>4.01 \mathrm{e}+01$ \\
\hline
\end{tabular}

Figure 10: Internal stresses of the structural members

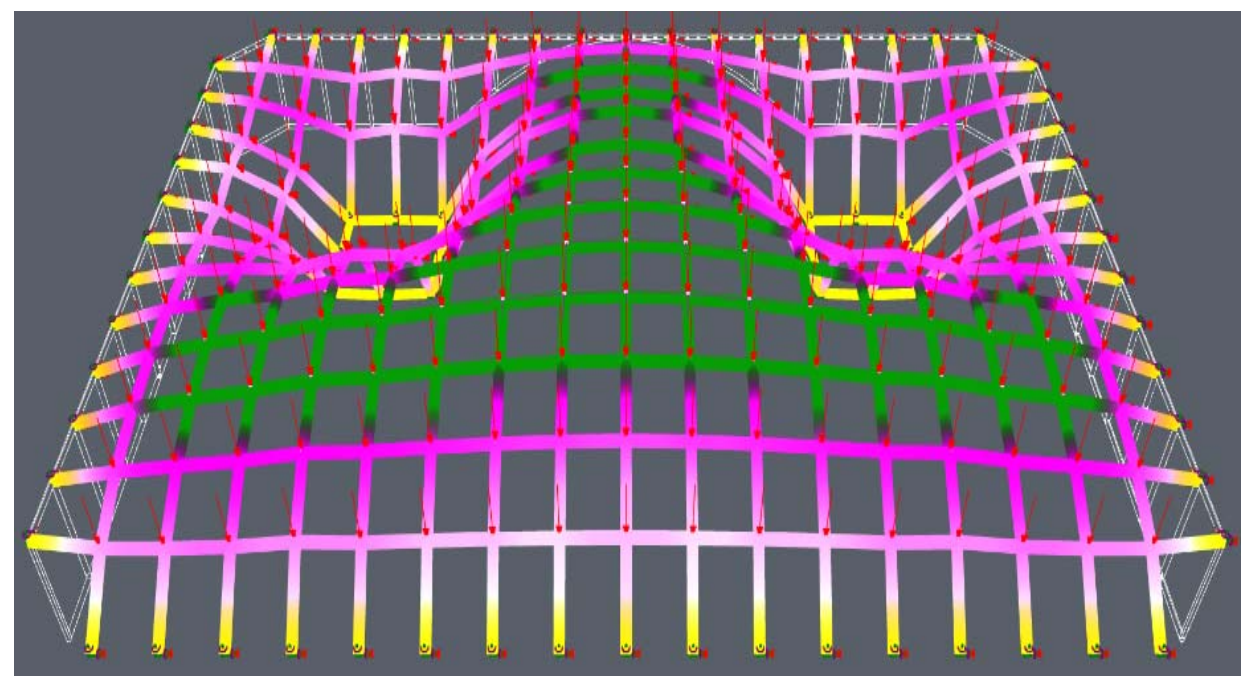




\begin{tabular}{|l}
$\mid$ res.disp. $[\mathrm{cm}]$ \\
\hline $2.06 \mathrm{e}-02$ \\
\hline $1.85 \mathrm{e}+00$ \\
\hline $3.68 \mathrm{e}+00$ \\
\hline $5.51 \mathrm{e}+00$ \\
\hline $7.34 \mathrm{e}+00$ \\
\hline $9.18 \mathrm{e}+00$ \\
\hline $1.10 \mathrm{e}+01$ \\
\hline $1.28 \mathrm{e}+01$ \\
\hline $1.47 \mathrm{e}+01$ \\
\hline $1.65 \mathrm{e}+01$ \\
\hline $1.83 e+01$ \\
\hline $2.02 \mathrm{e}+01$ \\
\hline $2.20 \mathrm{e}+01$ \\
\hline $2.38 \mathrm{e}+01$ \\
\hline $2.57 \mathrm{e}+01$ \\
\hline $2.75 \mathrm{e}+01$ \\
\hline $202 n+n 1$ \\
\hline
\end{tabular}

Figure 11: The displacement of structural members

\section{Earthquake loading}

Various parameters must be obtained to get the earthquake lateral forces in according to standard 2800.

\section{Project (A) base acceleration ratio}

Table 3: The base acceleration ratio of the project to gravity

\begin{tabular}{|c|c|c|}
\hline Area & Description & The base acceleration ratio of the project to gravity (A) \\
\hline 1 & Area with very high risk & 0.35 \\
\hline
\end{tabular}

\section{Reflection coefficient of building (B)}

Table 4: The reflection coefficient of the building

\begin{tabular}{|c|c|c|c|}
\hline Row & $\begin{array}{c}\text { Reflection coefficient of } \\
\text { building (B) }\end{array}$ & $\begin{array}{c}\text { Spectrum correction } \\
\text { factor (N) }\end{array}$ & $\begin{array}{c}\text { Spectral coefficient } \\
\text { (B1) }\end{array}$ \\
\hline 1 & 3.25 & 1 & 3.25 \\
\hline
\end{tabular}

\section{Basic shear force $\left(V_{u}\right)$}

Table 5: Basic shear force

\begin{tabular}{|c|c|c|}
\hline Row & $\begin{array}{c}\text { The final earthquake load by } \\
\text { applying the coefficient (E) }\end{array}$ & Base shear force (Vu) \\
\hline 1 & 212594 & 151853 \\
\hline
\end{tabular}

By obtaining the earthquake load, combining the loads is done repeatedly and examines the project resistance to the lateral load. The earthquake load is obtained after combining the load of $14105 \mathrm{kN}$ and should be applied in two directions perpendicularly and applied separately. In this section, the stability of the structure against earthquake loads is examined by graphs and numbers (Figure 12) and (Figure 13). 


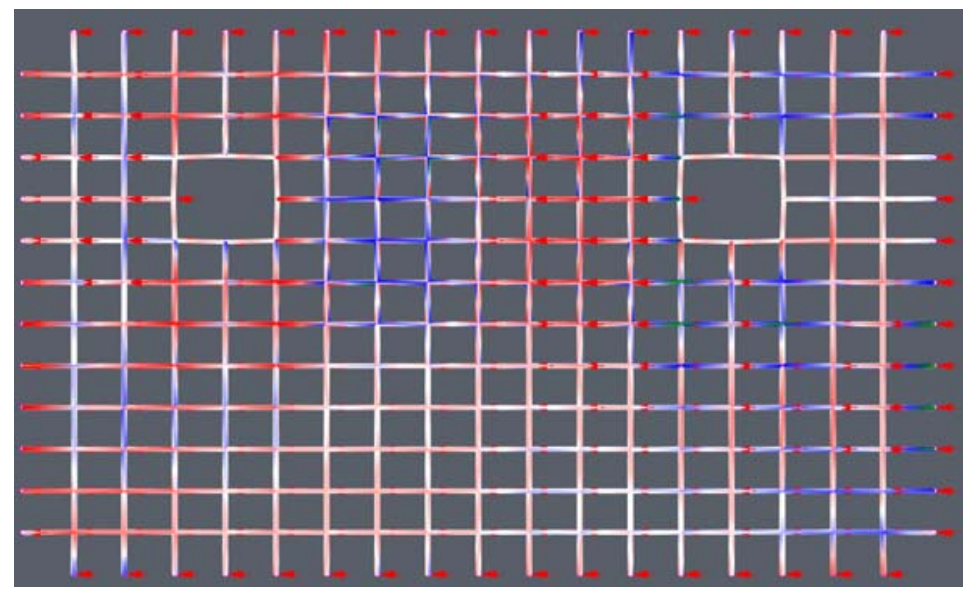

Figure 12: Loading in direction of southwards to north

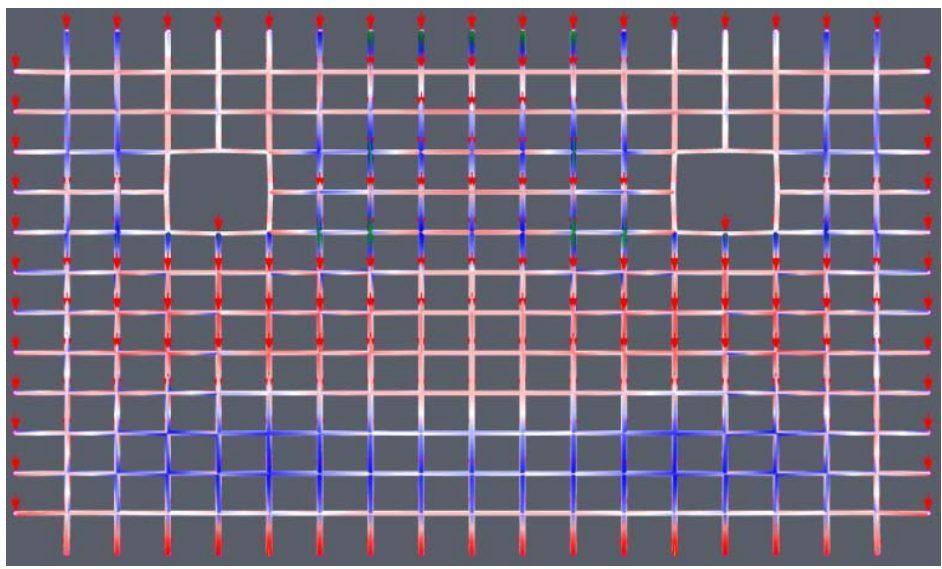

Figure 13: Loading in the direction of east to west

\begin{tabular}{|l|}
\hline stress[kN/cm2] \\
\hline$-2.62 \mathrm{e}+04$ \\
\hline$-2.29 \mathrm{e}+04$ \\
\hline$-1.96 \mathrm{e}+04$ \\
\hline$-1.64 \mathrm{e}+04$ \\
\hline$-1.31 \mathrm{e}+04$ \\
\hline$-9.82 \mathrm{e}+03$ \\
\hline$-6.55 \mathrm{e}+03$ \\
\hline$-3.27 \mathrm{e}+03$ \\
\hline $2.24 \mathrm{e}-12$ \\
\hline $1.65 \mathrm{e}+03$ \\
\hline $3.30 \mathrm{e}+03$ \\
\hline $4.95 \mathrm{e}+03$ \\
\hline $6.61 \mathrm{e}+03$ \\
\hline $8.26 \mathrm{e}+03$ \\
\hline $9.91 \mathrm{e}+03$ \\
\hline $1.16 \mathrm{e}+04$ \\
\hline$>1.32 \mathrm{e}+04$ \\
\hline
\end{tabular}

Figure 14: Stress in structure members during earthquake loading

\section{Input arch}

The dead load and the load applied from the structure to the arch is applied and the vault is loaded and analyzed by Karamba and its stability is examined (Figure 15). 


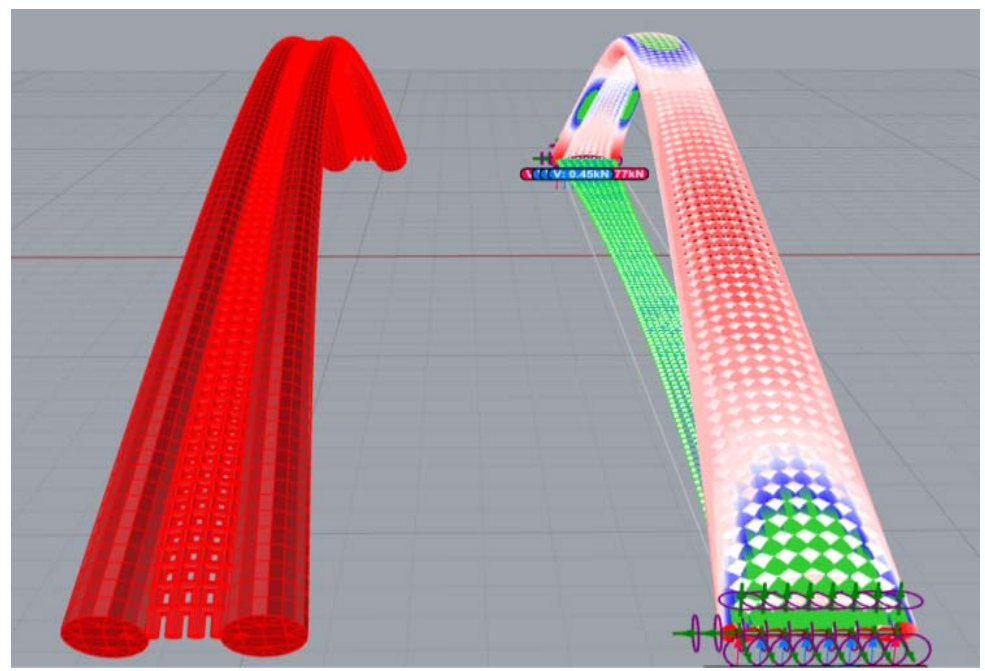

Figure 15: Reviewing the results of Rhino Vault and Karamba

The loads on the input vault are the total sum of the loads of 9 columns of the structure and the dead load of the arches (Table 6).

Table 6: The load applied on the vault

\begin{tabular}{|l|c|c|c|}
\hline Row & The final load on the vault (Kn) & Dead load (Kn) & Load from the structure (Kn) \\
\hline 1 & 7502 & 7352 & 150 \\
\hline
\end{tabular}

According to stress examination in Karamba, the section designed and proposed in Rhino Vault is the most suitable design stage and the materials used are of St-37 steel type. Due to the large size of the opening by loading in Rhino Vault, the critical sections are reached and their inside is reinforced with concrete until the critical area (Figure 16)

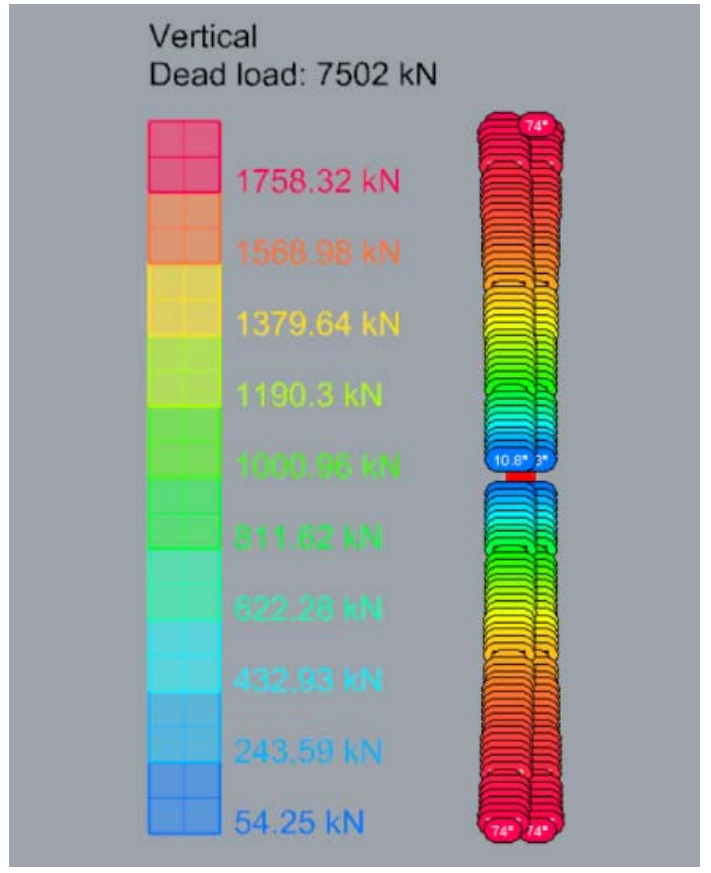

Figure 16: Rhino Vault output

According to the form and the previous discussion, the first one third element of the input vault from each side is reinforced with high-strength concrete. Finally, by calculating forces and designing 40 columns around the project, 8 of which are on the vault and transferring the load through the arc to the foundation, and 32 of them directly transfer the force to the foundation. From the west side (the park), there are also connections without columns and directly connected to the foundation designed in that section. 


\section{Persian vault buildings}

\section{Architectural parameters}

Besides the general form of the project, which is compressive, there is a large vault at the main entrance of the project with an opening of 40.9 and a height of 9.4 and a width of 2 meters, similar to the old structures such as Ivan Madaen - showing the peak of their designing power with a large vault, or the great arch of St. Louis in the present era displaying the peak of its architecture and engineering - the concept of the project is expressed that suggests the combination of traditional and new architecture, as well as a beautiful visual effect on the design.

\section{Green space}

One of the major goals of the architecture is that the project should fit well with the surrounding environment. As on the one direction, it is towards the great Laleh Park and in the other direction to Keshvarz Boulevard, both of which are very important and there is a lot of commuting there, facing the design from the park side a project is encountered that is like a member of the park, and when we enter, we encounter green space inside as well. On the other hand, when we enter from the street side, we encounter a modern building.

\section{The central courtyard}

Here, given the large size of the space and the combination of courtyards with vaults, which are a symbol of Iranian architecture, we have built two interior spaces as a central courtyard, as the people see the exhibit in the interior of the booths; they have the courtyards in front of them. The trees in this section can use rainwater and prevent the gathering of water in the area through drainage.

\section{Islamic ceiling designs}

In designing complex forms, we tend towards the parametric Grass Hopper plugin, so that by parametric design we get the design intended, which is based on the old Islamic Iranian models here, obtained with the combination of different geometries. Initially, we design a modulus from the model with Grass Hopper by graphical coding. In the next step, we define the obtained modulus through Grass Hopper for all the levels we want the model to be there and duplicate it in the design. As the design process is parametric, we can multiply the desired pattern according to the size of all levels that are different (Figure 17).

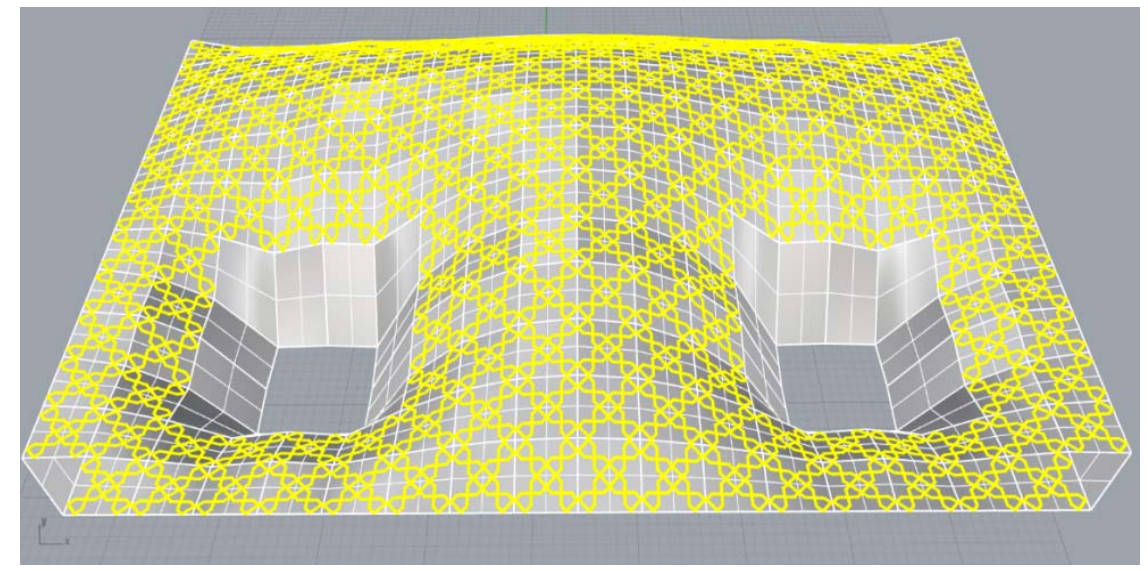

Figure 17: Islamic ceiling design patterns

\section{Interior design}

We have wide-open space on the ground floor, which is suitable for designing booths and designed in the buildings of the project in different classes of amphitheater, conference hall, service spaces, facilities and warehouses. There are various accesses to these spaces. We will discuss the list of spaces and accesses. On the ground floor, there is a space for booths and part of service spaces (Figure 18). 


\begin{tabular}{l} 
Exhibition \\
Green space \\
Restaurant \\
Office \\
Installation \& Store \\
Access \\
Entrance \\
\hline
\end{tabular}

\section{Sunlight}

Tailored to the design of the exhibition use, sunlight is used for lighting and heat in cold seasons using a lot of glass cover. However, in proportion to it, the intense and annoying sunlight in the warm seasons and intense and annoying rays should be considered. Thus, by path the direction and direction of the sun's motion at different times and the amount of received sunlight by the structure, we look at the information obtained from the design of the appropriate veneer in areas where there is intense and annoying light. Then, by getting the output of Lady Bug plugin, we examine the issues raised. In the first study, we take an output of radiation over a year and see at which places we always have sunlight and at which places not (Figure 19)

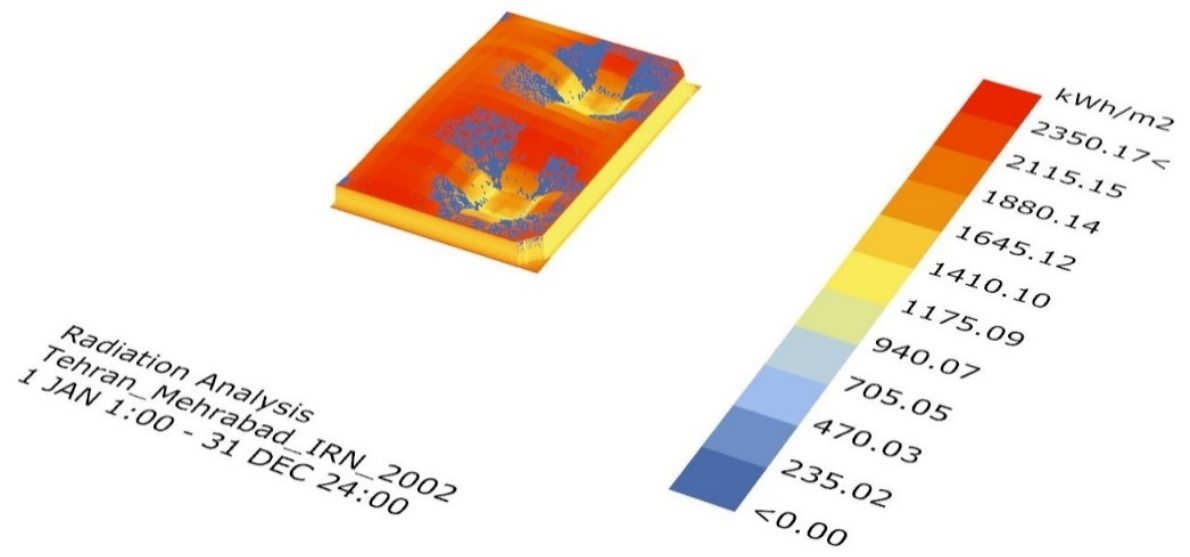

Figure 19: The sunlight received by the structure 
In the next figure, we examine the disturbing sunlight in the summer (Figure 20).
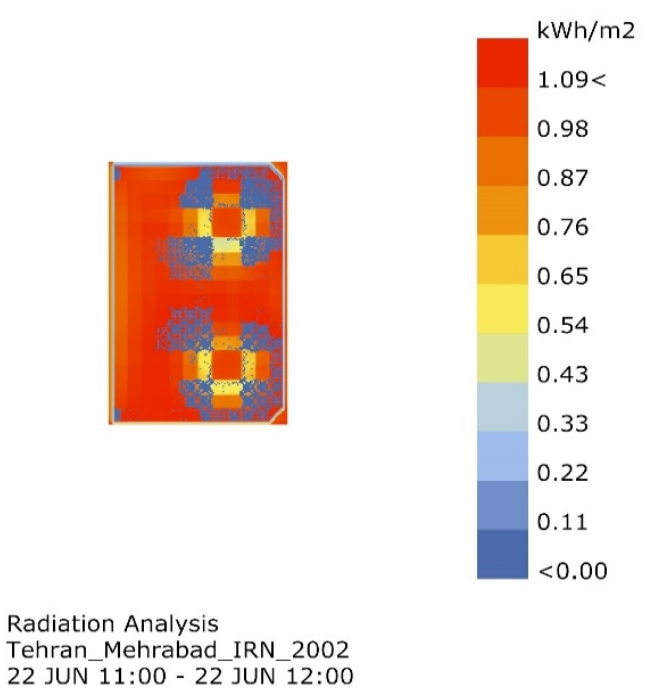

Figure 20: Annoying sunlight in the summer

As is seen, in the warmest season of the year, the greatest radiation is on the south side of the ceiling and the central sections between the two central courtyards. After examining the walls, covering type to prevent disturbing light in these sections will be examined (Figure 21).

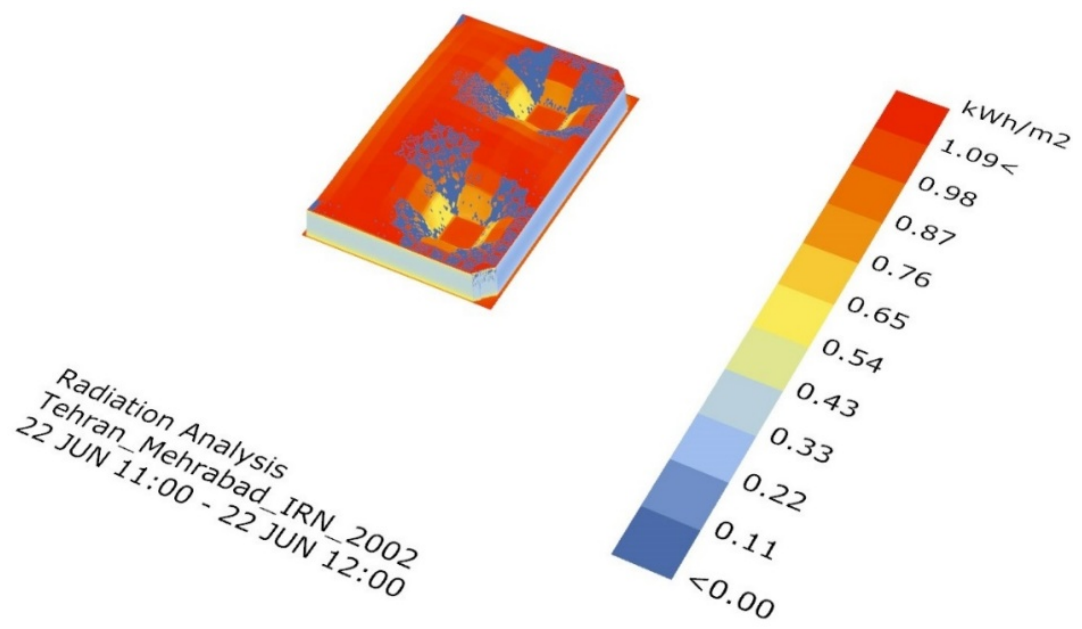

Figure 21: South and East sides

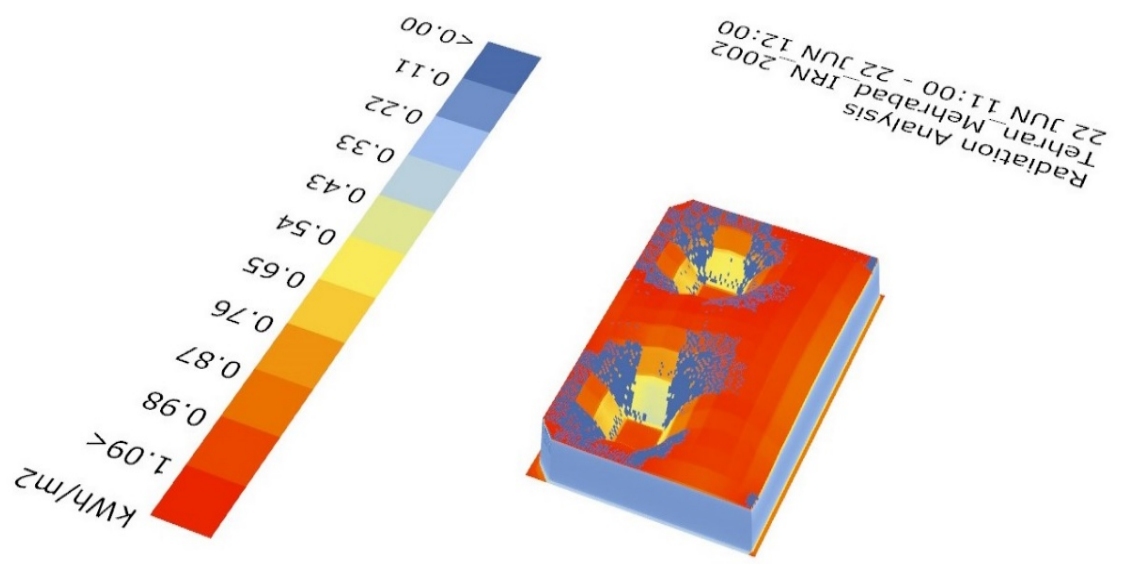

Figure 22: North and West sides

As is seen in the above figures, there is no disturbing light in the walls (Fig. 22). Thus, we must only have a canopy in the ceiling areas with intense light and use shutter shades in the areas mentioned. 


\section{Design plan}

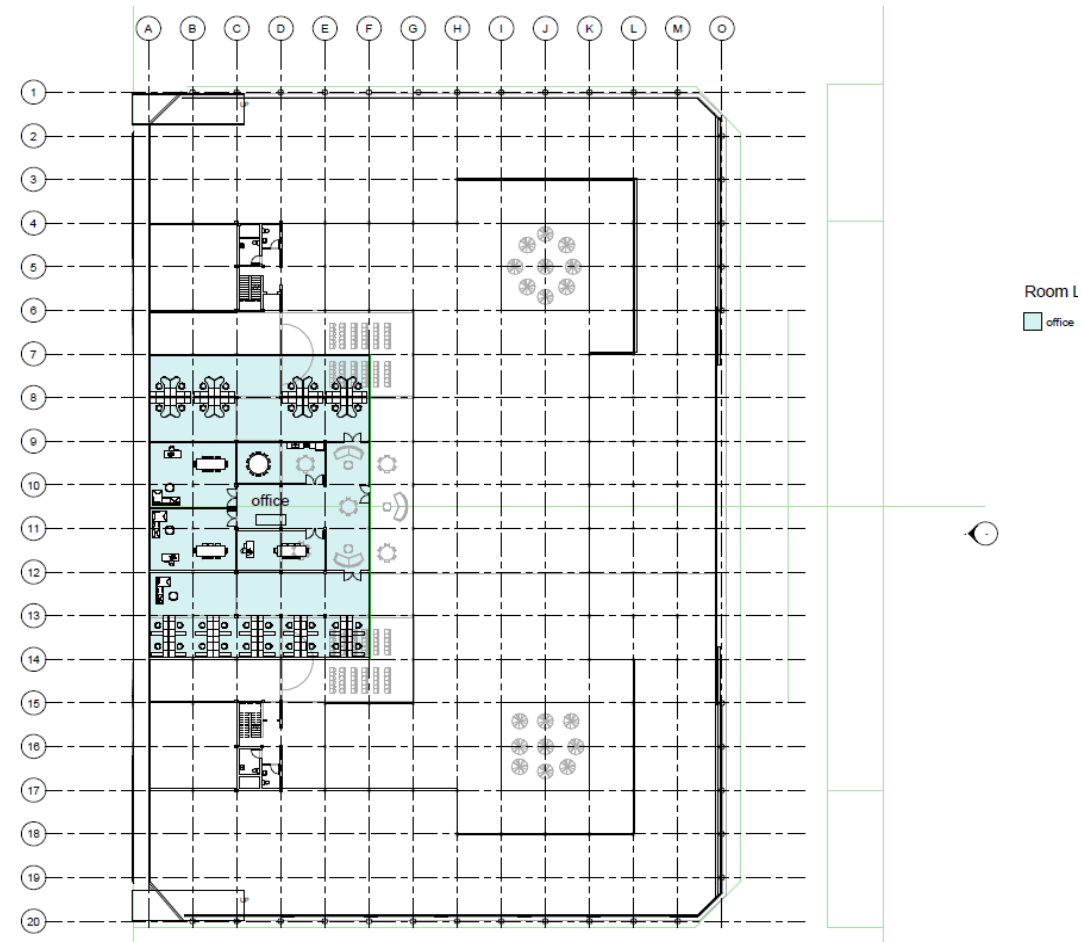

(1) First Floor

Figure 23: First floor plan

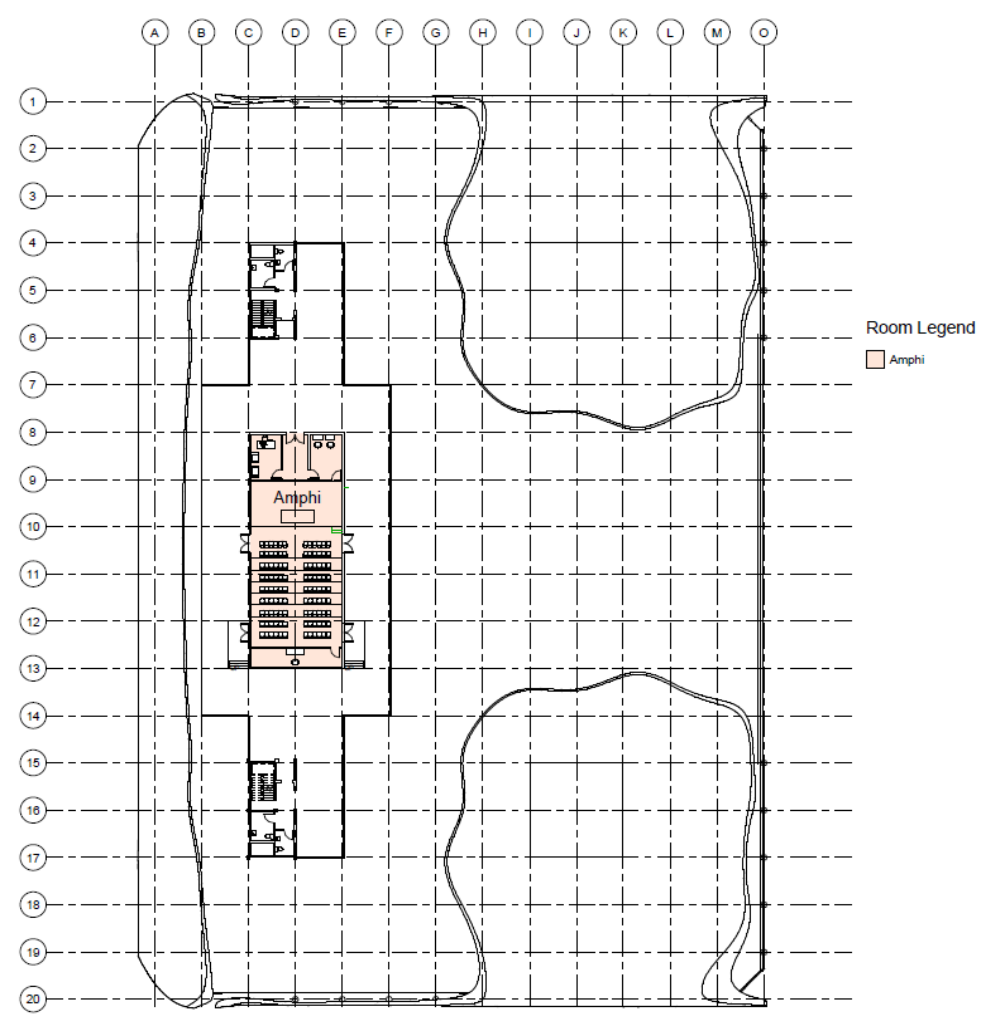

(1) $\frac{\text { Second Floor }}{1: 200}$

Figure 24: Second floor plan 


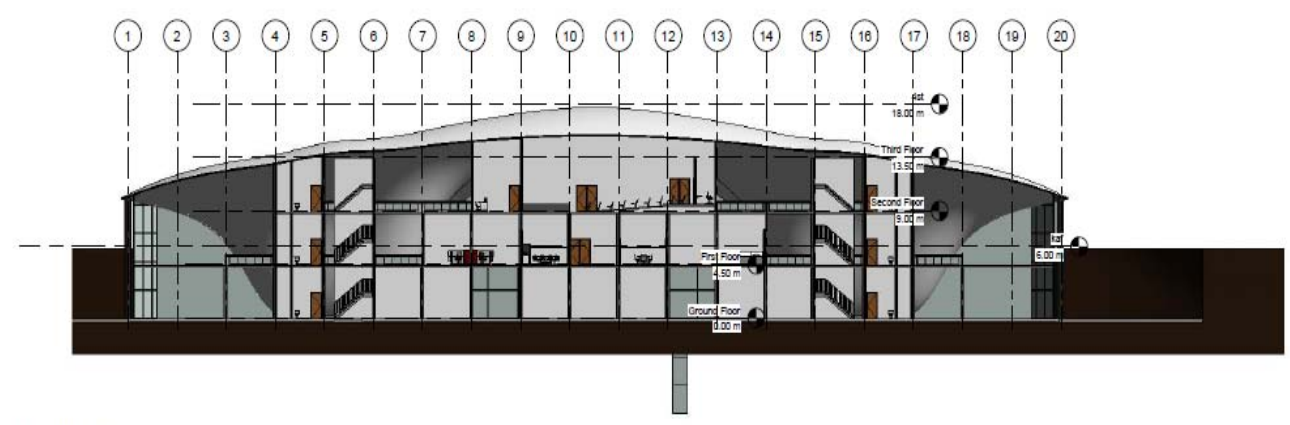

(1) $\frac{\operatorname{Section} A}{1: 200}$

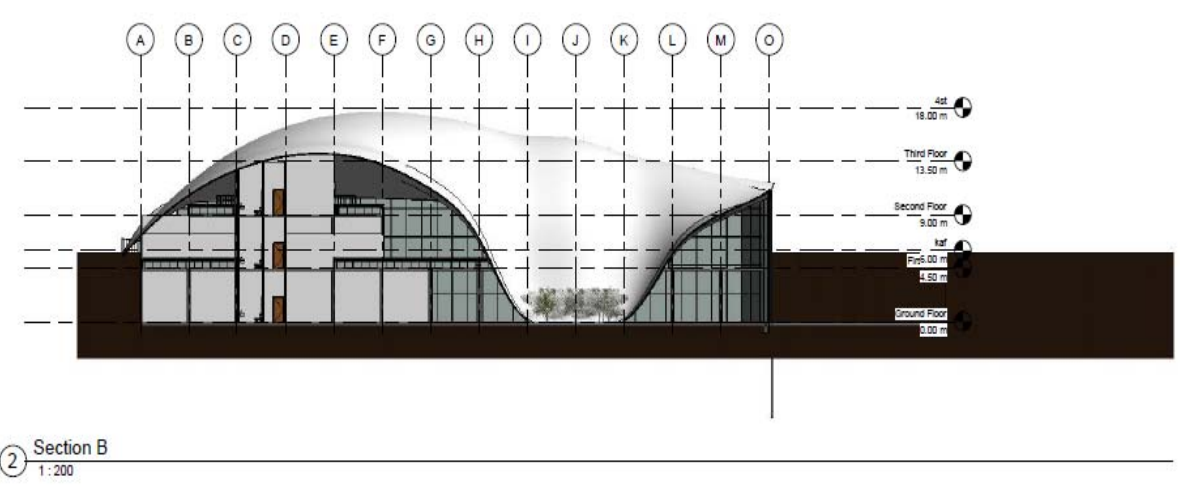

Figure 25: Section in two directions perpendicular to each other

\section{References}

[1] Golabchi, M., Taghizadeh, K., Golabchi, M.R., (2013) Construction systems

[2] Golabchi, M., Taghizadeh, K., Golabchi, M.R. (2013). Digital Architecture: Application of CAD, CAM, CAE in Architecture. Tehran: Tehran University Press.

[3] Goldberg, M., Lorimir, J. (2001). Trade fairs and hidden values in instability periods, Mashhad International Exhibition

[4] Cuttler, Ph., Armstrong, G. (1999). Principles of Marketing, Translation of Parsian Ali, Tehran, New World

[5] Khabbazi, Z. (2012). Algorithmic architecture paradigm. Mashhad: Frazadeh Book Publishing.

[6] Skip Cox, Beyond ROI and ROO: Using Measurement to Enhance Decisions \& Improve Exhibit Results, President, Exhibit Surveys, Inc, June, 2003

[7] Association of Exhibition Organizers (AEO). (2003). “Job opportunities in fair industry”. Hong Kong: Media Center, pp: 27-31 .

[8] A., Nicknam; Y., Eslamian; A Hybrid Method for Simulating Near-source, Broadband Seismograms:Application to the 2003 Bam Earthquake (Mw 6.5), Tectonophysics, Vol. 487, No. 1, pp. 46 58, 2010. 